\title{
The pattern of maxillofacial fractures in central India A Unicentric retrospective study
}

\author{
Dr. Rajanikanth K,.Dr.R..M.Borle,Dr.Nitin Bhola,Dr.Shivam \\ Deparment of Oral and maxillofacial surgery Sharad Pawar Dental college Sawangi (Meghe) Wardha M.H.
}

\begin{abstract}
Aim of the present retrospective analysis of data was to analyze the incidence and pattern of maxillofacial fractures based on the age and sex distribution, aetiology, site, distribution.

Study was conducted in the department of Oral and Maxillofacial Surgery in Aacharya Vinoba Bhave Rular hospital Sawangi (Meghe) Wardha Nagpur. Retrospective data retrieved of all the patient reporting to our hospital between January 2008 to December 2012 was carried out. Total 1182 patient with 1590 fractures were treated out of which isolated mandibular fracture were most frequent 898 in 746 patients, mid face fractures 693 in 436 patients and both mandible and mid face fractures were 624 in 452 patients. Among zygomatic bone, maxillary fractures nasal bone and zygomatic arch fractures were most common.

Road traffic accident is the major etiological factor with a male predominance and the peak incidence during 20-40 years of age.

Motor vehicle collisions constituted the highest incidence as a cause of traumatic maxillofacial injuries followed by fall from height, assault and sport related injuries in young population.
\end{abstract}

\section{Introduction}

Maxillofacial region (MFR) involves soft and hard tissues forming the face extending from frontal bone superiorly to the mandible inferiorly. The face being the most exposed part of the body is particularly prone to trauma. Trauma to the facial region causes injuries to skeletal components, dentition as well as soft tissues of the face. Injuries to the maxillofacial region are increasing in frequency and severity because of the heavy reliance on road transportation and the increasing socioeconomic activities of the population $\left({ }^{1,2,3}\right)$

Every 30 seconds someone dies on the world's roads. Annually over 1 million people die and over 25 million are injured or permanently disabled from road traffic injuries. ${ }^{(4)}$ The primary cause of maxillofacial fractures throughout the world is road traffic accidents and assaults. $\underline{\underline{5}}$

The severity and pattern of the fracture will depend on the magnitude of the causative force, impact duration, the acceleration impaired by it to the part of the body struck and the rate of acceleration change. The surface area on which the impact strikes is also relevant.(6)

The aim of the present study is to analyze retrospectively the age and sex distribution, aetiology and location of mandibular and midface fractures in a sample of patients visited in Acharya Vinoba Bhave Rular hospital Sawangi ( Meghe) Wardha between January 2008 to December 2012.

The following parameters were taken into account

\section{Aims and Objectives}

- Age and sex distribution of maxillofacial trauma.

- Etiological factors causing maxillofacial trauma.

- Incidence of maxillofacial trauma due to road traffic accidents

- Pattern and demographic distribution of fractures at different sites of the maxillofacial skeleton.

\section{Patients and Methods}

The data for this study were obtained from the medical records of 1182 cases treated at Acharya Vinoba Bhave Rular hospital Sawangi ( Meghe) Wardha during the period of January 2008 to December 2012., Data were collected regarding gender, age, mechanism of injury, associated injury and fracture area of maxillo facial region.

The diagnosis of a fracture is based on the clinical history, signs and symptoms, visual finding, manual examination and correct interpretation of radiographs. The pattern of facial fractures is determined according to the fractures of mandible, and mid face in relation to the different etiological factors.

For this study, the mandible was divided into condylar, coronoid, angle, body, symphyseal, and dentoalveolar regions. In the middle-third of the face, fractures were recorded as Le Fort, I, II, and III types, zygomatic bones, nasal bones, naso -orbito- ethmoidal complex, orbital blow-out, and dentoalveolar fractures

Etiological factors were classified as road traffic accidents, fall from height and assault and sports injuries.

Soft tissue lacerations were not recorded as associated injuries 


\section{Results}

Between January 2008 to December 2012, a total of 1590 maxillofacial fractures and associated injuries were collected in 1182 patients and analyzed, giving a yearly total of 318 fractures.

\section{Annual Incidence:-}

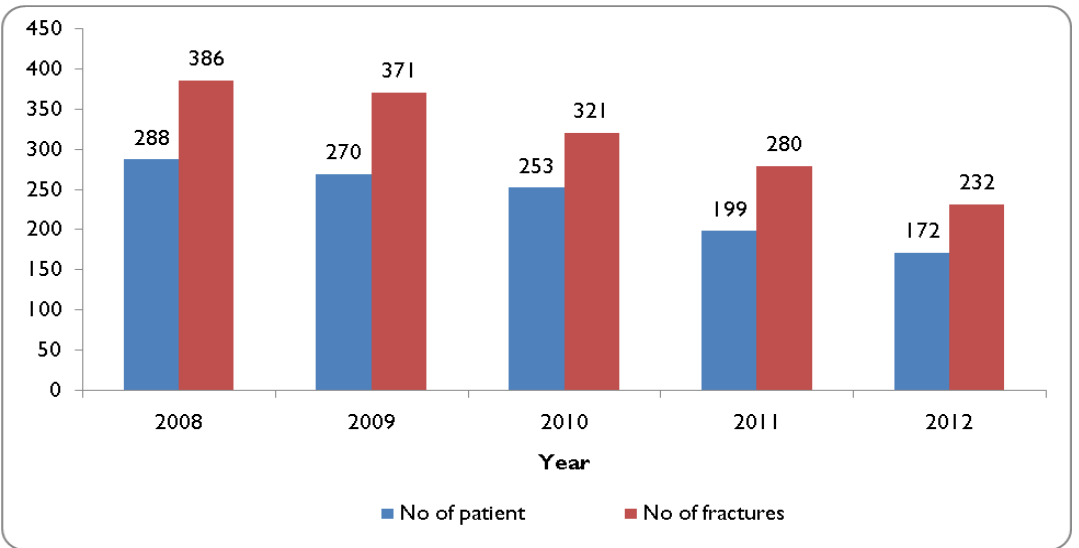

Patients' ages ranged from 3 to 65 years (mean 30), There was an overwhelming male preponderance in all age groups The overall male:female ratio was 4.9:1

Age and sex distribution:-

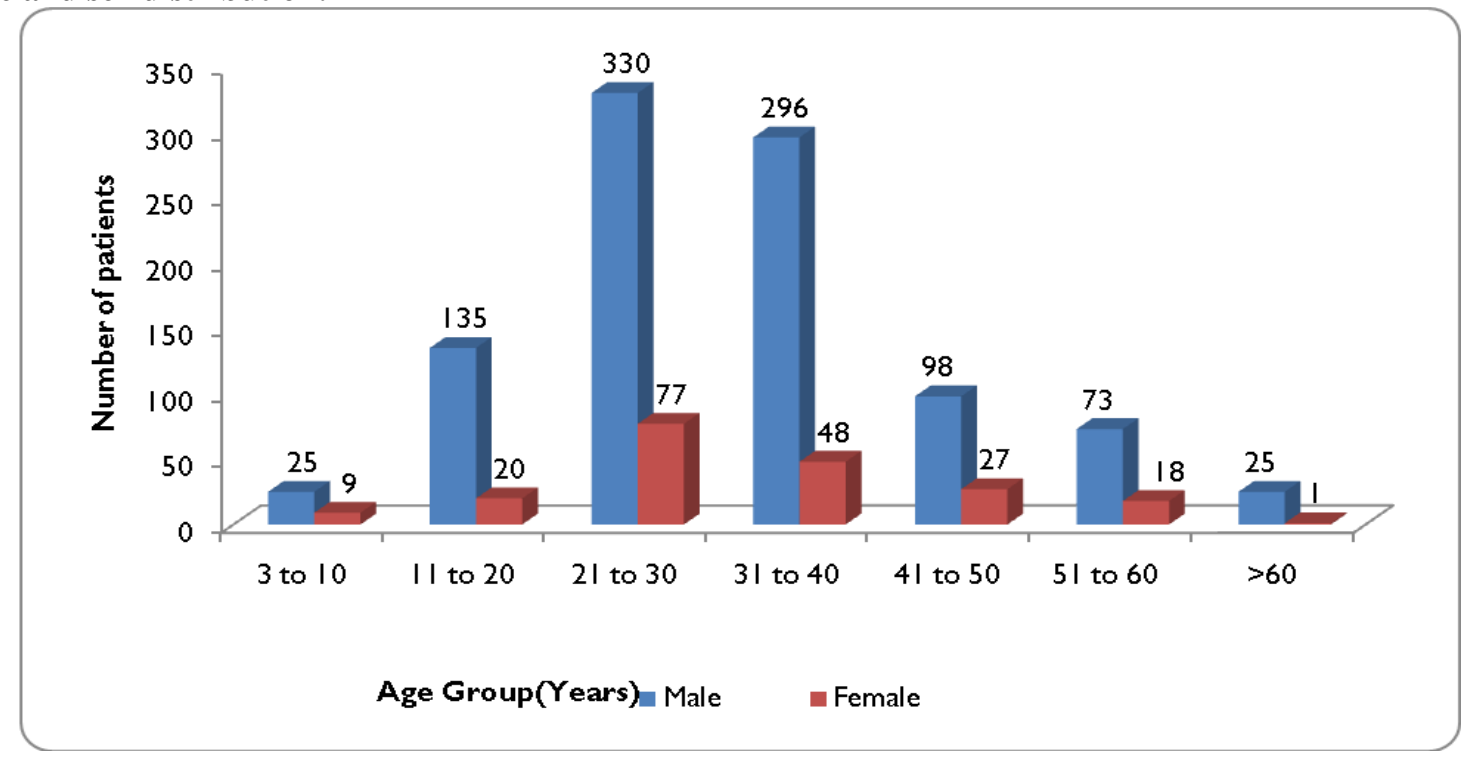

Fracture pattern and cause of injury-

Isolated mandibular fractures were most frequent, 898 seen in 746 patients $(56.4 \%)$ followed by isolated mid face fractures in 639 in 436 patients $(40.18 \%)$. In isolated mandibular fractures data shows parasymphysis area were the most common site for fracture (32.51\%) followed by the mandibular condyle (18.26\%)

Site distribution in mandible:-

\begin{tabular}{|l|l|l|l|l|l|l|l|}
\hline Site & $\mathbf{2 0 0 8}$ & $\mathbf{2 0 0 9}$ & $\mathbf{2 0 1 0}$ & $\mathbf{2 0 1 1}$ & $\mathbf{2 0 1 2}$ & Total & \% \\
\hline Symphysis & 17 & 17 & 09 & 11 & 08 & $\mathbf{6 2}$ & $\mathbf{6 . 9 0}$ \\
\hline Parasymphysis & 62 & 63 & 62 & 60 & 45 & $\mathbf{2 9 2}$ & $\mathbf{3 2 . 5 1}$ \\
\hline Body & 28 & 29 & 22 & 15 & 21 & $\mathbf{1 1 5}$ & $\mathbf{1 2 . 8 0}$ \\
\hline Condyle & 33 & 40 & 28 & 34 & 29 & $\mathbf{1 6 4}$ & $\mathbf{1 8 . 2 6}$ \\
\hline Angle & 35 & 40 & 35 & 32 & 14 & $\mathbf{1 5 6}$ & $\mathbf{1 7 . 3 7}$ \\
\hline Dentoalveolar & 28 & 26 & 20 & 15 & 19 & $\mathbf{1 0 8}$ & $\mathbf{1 2 . 0 2}$ \\
\hline Coronoid & & & 1 & & & $\mathbf{1}$ & $\mathbf{0 . 1 1}$ \\
\hline Total & $\mathbf{2 0 3}$ & $\mathbf{2 1 5}$ & $\mathbf{1 7 7}$ & $\mathbf{1 6 7}$ & $\mathbf{1 3 6}$ & $\mathbf{8 9 8}$ & \\
\hline \% & $\mathbf{2 2 . 6 0}$ & $\mathbf{2 3 . 9 2}$ & $\mathbf{1 9 . 7 1}$ & $\mathbf{1 8 . 5 9}$ & $\mathbf{1 5 . 1 4}$ & & \\
\hline
\end{tabular}


In this study total 692 mid face fractures in 436 patients were analyzed. In the middle third of facial skeleton zygomatico - maxillary complex fracture were more common (30.92\%) followed with Lefort fractures $26.72 \%$

Mid face site distribution:

\begin{tabular}{|l|l|l|}
\hline Site & Fractures & \% \\
\hline Lefort I & 54 & 7.80 \\
\hline Lefort II & 79 & 11.41 \\
\hline Lefort III & 52 & 7.51 \\
\hline Zygoma (ZMC) & 214 & 30.92 \\
\hline NOE & 22 & 3.17 \\
\hline Nasal & 96 & 13.87 \\
\hline Dentoalveolar & 47 & 6.7 \\
\hline Zygomatic arch & 51 & 7.36 \\
\hline Orbital blow out & 46 & 6.64 \\
\hline Frontal & 31 & 4.47 \\
\hline Total \# & $\mathbf{6 9 2}$ & \\
\hline
\end{tabular}

Traffic accident related fractures occurred in $1014(85.09 \%)$ patients. The largest proportion of traffic accident related injury involved motorcycles. The second most common cause of facial fractures was fall from height ( 94 patients $8.29 \%$ ) followed by assault (74 patients $6.52 \%$ ).

Etiology:-

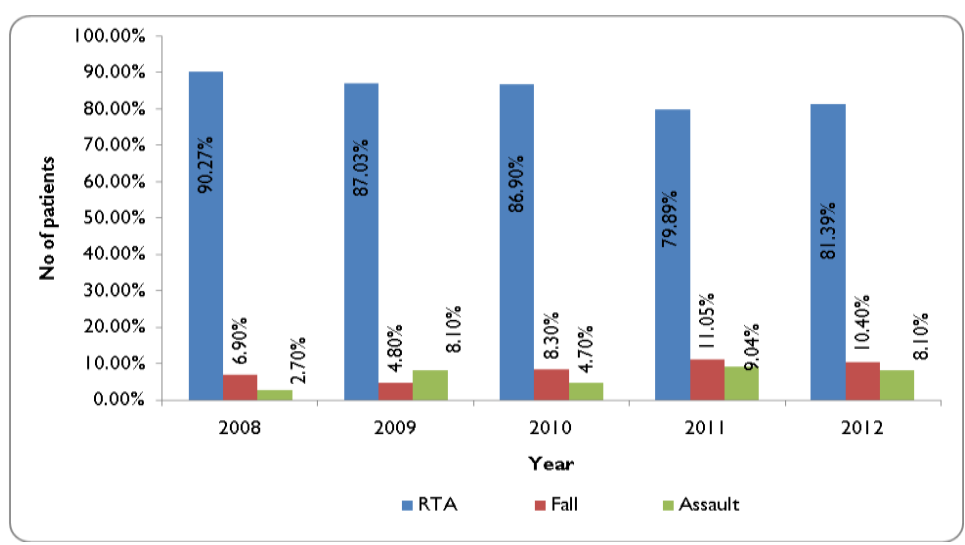

\section{Discussion}

This study showed that the maxillofacial fractures predominantly occurred in the age group of 21-30 years $(34.43 \%)$, followed by $31-40$ years $(29.10 \%)$ and $11-20$ years $(13.1 \%)$. These findings being similar with the previous studies. ${ }^{(7,8,9,10,11)}$ The high incidence in $3 \mathrm{rd}$ decade of life might be due to the facts that people belonging to this decade are more active, energetic, take active participation in dangerous exercises and sports activities and mostly involved in violence. Men aged 21-40 years represent a group with intense social interaction and higher rates of morbidity, making them more susceptible to transport accidents and interpersonal violence. (12)

The low incidence in 3-10 (2.87\%) years has been explained by the high elasticity of children's bones, the smaller face relative to head size and a decreased exposure to major trauma. (13)

An incidence of $2.19 \%$ was noted for geriatric ( $>60$ years) maxillofacial fractures in this study, probably as this age group is less active and less involved in outdoor activities. Similar incidence was found by Kadkhodaie $\mathrm{MH}$ in Iran (14) and Mahmeed BEA in Kuwait. (15)

In men as compared to women the incidence of maxillofacial fractures had a ratio of 4.9: 1. This can be explained by the fact that men are more involved in outdoor activities and are also exposed to violent interactions as compared to females who are less exposed due to social and religious limitations. Male vehicle drivers also far outnumber females. Similar ratio of 4:1 has been found in Finland by Salonem EM in 2010.(16) According to this study, $85.09 \%$ maxillofacial fractures were caused by road traffic accidents followed by falls $(8.29 \%)$ and assaults $(6.52 \%)$. Road traffic accidents are the main cause of maxillofacial trauma. The reasons for higher frequency of RTA in developing countries are inadequate road safety awareness, unsuitable road conditions without expansion of the motorway network, violation of speed limit, old vehicles without safety features, not wearing seat belts or helmets, violation of highway code and use of alcohol or other intoxicating agents.(17) 
Two wheelers were responsible for the majority of road traffic accidents probably because two wheelers are very popular as a mode of transport due to their fuel efficiency and ease of use in congested traffic (18)

Mandibular fractures (56.4\%) accounted for highest number of fractures due to RTA followed by middle third fractures $(30.92 \%)$ in our study. mandibular fractures were more common than the middle third fractures Mandible, being the most prominent bone in face, is often fractured more than the strongly supported middle third of the face

In the present series, among the mandibular fracture sites, parasymphysis $(32.51 \%)$ was the most common fracture site followed by the condyle $(18.26 \%)$. The location of fracture site appears to be directly related to the cause of injury in some instances and probably reflects the direction from which force was applied to the mandible

In our study, in middle third fractures, ZMC (30.92) was most commonly involved. This is because of the prominent positions; zygomatic bone and nasal bone are more vulnerable to trauma followed by lefort fractures.

\section{Conclusion}

In this retrospective survey of 1182 cases of facial fractures in central india between 2008 to 2012, the most common cause found was traffic accidents. Majority of the patients were driving two wheelers and most were under the effect of alcohol. Most of the injuries occurred during night and road traffic accidents were found to be the major etiological factorThe second most common cause was a fall from height followed by assault. Most fractures occurred in the age range of 20-30 years. The mandible was the most frequent site involved. Among maxillary fractures, zygomatic bone and arch fractures were most common

Care of injured patients should include not only management of the acute phase, but also combine preventive programs and interventional programs aimed at reducing the incidence of maxillofacial fractures. Therefore, there is a need to ensure strict compliance of traffic rules and regulations, implement improvement in automotive safety devices, organize prevention programs to minimize assaults, implement school education in alcohol abuse and handling potentially hostile situations (especially for men), improve protection during sporting activities, and legislate wearing of protective headgear in workers. Preventive strategies remain the cheapest way to reduce direct and indirect costs of the sequelae of trauma. Societal attitudes and behaviors must be modified before a significant reduction in the incidence of maxillofacial fractures will be seen.

\section{References}

[1.] Chandra Shekar BR, Reddy C. A five-year retrospective statistical analysis of maxillofacial injuries in patients admitted and treated at two hospitals of Mysore city. Indian J Dent Res. 2008 Oct;19(4):304-8.

[2.] Fonseca RL, Walker R, Betts NJ. Oral and maxillofacial trauma, 2nd ed. Philadeiphia: WB Saunders, 1997

[3.] A comprehensive study on maxillofacial trauma conducted in Yamunanagar, India

[4.] Rishi Bali,,${ }^{a,}$ Parveen Sharma, ${ }^{a}$ Amandeep Garg, ${ }^{a}$ and Guneet Dhillon ${ }^{a}$

[5.] Mohan D. Transportation Research and Injury Prevention Programe (TRIPP). Bulletin. 2006;3(3):1-2.

[6.] Oji C. Jaw fractures in Enugu, Nigeria, 1985-95. Br J Oral Maxillofac Surg. 1999 Apr;37(2):106-9.

[7.] Rowe et al 1994; Simpson and mclean 1995

[8.] Bataineh AB. Etiology and incidence of maxillofacial fractures in the north of Jordan. Oral Surg Oral Med Oral Pathol Oral Radiol Endod. 1998 Jul;86(1):31-5.

[9.] 8.. Fasola AO, Nyako EA, Obiechina AE, Arotiba JT. Trends in the characteristics of maxillofacial fractures in Nigeria. J Oral Maxillofac Surg. 2003 Oct;61(10):1140-3

[10.] 09. Al-Khateeb T, Abdullah FM. Craniomaxillofacial injuries in the United Arab Emirates : a retrospective study. J Oral Maxillofac Surg. 2007 Jun;65(6):1094-101.

[11.] 10. Olasoji HO, Tahir A, Arotiba GT. Changing pictures of facial fractures in northern Nigeria. Br J Oral Maxillofac Surg. 2002 Apr;40(2):140-3. [PubMed]

[12.] 11. Adebayo ET, Ajike OS, Adekeye EO. Analysis of the pattern of maxillofacial fractures in Kaduna, Nigeria. Br J Oral Maxillofac Surg. 2003 Dec;41(6):396-400. [PubMed]

[13.] 12 Brasileiro BF, Passeri LA. Epidemiological analysis of maxillofacial fractures in Brazil: a 5-year prospective study. Oral Surg Oral Med Oral Pathol Oral Radiol Endod. 2006 Jul;102(1):28-34

[14.] Adeyemo WL, Iwegbu IO, Bello SA, Okoturo E, Olaitan AA, Ladeinde AL, et al. Management of mandibular fractures in a developing country: a review of 314 cases from two urban centers in Nigeria. World J Surg. 2008 Dec;32(12):2631-5. [PubMed]

[15.] 14. Kadkhodaie MH. Three-year review of facial fractures at a teaching hospital in northern Iran. Br J Oral Maxillofac Surg. 2006 Jun;44(3):229-31. [PubMed]

[16.] 15. Al Mahmeed BE, Morris RE, Ibrahim M, Belal MS, Al Ramzy A, Al Rassed B, et al. Maxillofacial trauma in Kuwait : a retrospective study (1985-1989). Saudi Denta J. 1994;6:13-6.

[17.] 16. Salonen EM, Koivikko MP, Koskinen SK. Violence-related facial trauma: analysis of multidetector computed tomography findings of 727 patients. Dentomaxillofac Radiol. 2010 Feb;39(2):107-12.

[18.] 17. Ansari MH. Maxillofacial fractures in Hamedan province, Iran: a retrospective study (1987-2001). J Craniomaxillofac Surg. 2004 Feb;32(1):28-34. [PubMed]

[19.] 18. Tripude BH, Naik RS, Anjankar AJ, Khajuria BK. A study of the pattern of cranio-cerebal injuries in road traffic accident. Journal of Indian Academy of Forensic Medicine. 1998;20(1):9-12 